\title{
CAPITALISMO CONSCIENTE \\ UMA CONFIGURAÇÃO MAIS JUSTA OU A ARTE DE SE REINVENTAR PARA CONTINUAR A EXISTIR?
}

\section{CONSCIOUS CAPITALISM \\ A FAIRER CONFIGURATION OR THE ART TO REINVENT ITSELF TO KEEP EXISTING?}

\author{
Marcos da Silva Lima \\ Departamento de Sociologia, Instituto de Ciências Sociais, Universidade do Minho. Campus de Gualtar 4710 - \\ 057 Braga, Portugal. Email: marcosdslima@gmail.com

\section{Fernando Bessa Ribeiro} \\ Departamento de Sociologia, Instituto de Ciências Sociais, Universidade do Minho \& Centro Interdisciplinar de \\ Ciências Sociais - Polo da Universidade do Minho (CICS.NOVA.UMinho). Campus de Gualtar 4710 - 057 Braga, \\ Portugal. Email: fbessa@ics.uminho.pt
}

\begin{abstract}
Resumo: Se é pertinente reconhecer que o capitalismo não desapareceu destruído pelas suas contradições e a degradação progressiva das condições necessárias à sua reprodução, não é menos relevante sublinhar a sua enorme capacidade para se reinventar a cada crise e mesmo fora delas. Tão frequente como as crises, são as inovações teóricas que procuram dar novas configurações ao capitalismo na sua permanente luta para ser aquilo que, acusam os críticos, não pode ser nem escapar: um sistema menos desigual e socialmente mais justo, onde a procura da mais-valia não se constitua na motivação principal dos capitalistas. É o caso do chamado "capitalismo consciente". Este artigo tem por objetivo escrutinar as origens do conceito de capitalismo consciente e os principais argumentos usados em seu favor. Este exercício crítico procura identificar se estamos, de facto, perante uma nova configuração do capitalismo ou, pelo contrário, se trata de mais uma reinvenção para continuar a existir.
\end{abstract}

Palavras-chave: capitalismo consciente, desigualdades sociais, crise, reconfiguração.

\begin{abstract}
If it is pertinent to recognize that capitalism did not disappear destroyed by its contradictions and the progressive degradation of the conditions necessary for its reproduction, it is no less relevant to underline its enormous capacity of reinvention in every crisis and beyond. As often as the crises, theoretical innovations have been seeking to give new configurations to capitalism in its ongoing struggle to be what, as critics have accused, can neither be nor escape: a less unequal and socially fairer system, where the search for surplus value is not capitalists' main motivation. This is the case of the so-called "conscious capitalism". This paper scrutinizes the origins of the concept of conscious capitalism and the main arguments used in its favor. This critical exercise seeks to identify whether we are really facing a new configuration of capitalism or, on the contrary, whether it is yet another reinvention of itself.
\end{abstract}

Keywords: conscious capitalism, social inequality, crisis, reconfiguration.

\section{Introdução}

Se é pertinente reconhecer que o capitalismo não desaparecerá destruído pelas suas contradições e a degradação progressiva, nomeadamente ecológica, das condições 
necessárias à reprodução da acumulação, não é menos pertinente ainda sublinhar a sua enorme capacidade para se reinventar a cada crise e mesmo fora dela. As "sete vidas" do capitalismo, como escreveu há já mais de duas décadas Arrighi (1997), exprimem justamente a sua adaptação e flexibilidade. Esta capacidade de se reinventar não deixa de contribuir decisivamente para a sua sobrevivência, eliminando ou incorporando a contestação para lhe retirar eficácia, não obstante as lutas pela sua superação levadas a cabo pelas classes trabalhadoras e seus partidos políticos, sindicatos e outros movimentos sociais. Daqui não decorre, como veremos, aceitar qualquer tipo de fatalismo ou, ainda de modo mais decisivo, não reconhecer o capitalismo como uma construção humana, logo histórica. Assim, não é descartável a sua substituição por um outro sistema, dependendo a possibilidade socialista da perseverança da ação coletiva organizada comprometida com um projeto emancipatório anticapitalista.

Tão frequente como as crises são as inovações teóricas que procuram dar novas configurações ao capitalismo na sua permanente luta para ser aquilo que, acusam os críticos, não pode ser, nem escapar: um sistema menos desigual e socialmente mais justo, no qual a procura da mais-valia não se constitua como a motivação principal dos capitalistas. Entre as propostas mais recentes encontramos as do "capitalismo cívico" (Hay \& Payne, 2015) ${ }^{1}$ e do "capitalismo consciente" (Mackey \& Sisodia, 2013). Centrando a nossa atenção neste último, o conceito foi apresentado na década passada, propondo um modelo de funcionamento no qual o lucro não é o objetivo fundamental das empresas. Esta nova conceção de capitalismo sustenta-se na ideia de que o lucro é consequência de uma ação orientada para um propósito maior. Este propósito justifica a existência de empresas vinculadas à geração de valor para todas as partes envolvidas no processo de produção e comercialização, inscrevendo-se, assim, no compromisso de construção de um mundo melhor.

Este texto tem por objetivo escrutinar as origens do conceito de capitalismo consciente e os principais argumentos que permitem defini-lo, segundo os seus proponentes, como uma nova configuração do capitalismo. No seu discurso otimista, o capitalismo consciente constitui um modelo mais justo de capitalismo, ciente das desigualdades provocadas pelo seu funcionamento e, assim, comprometido com a sua redução. Por outras palavras, esta consciência será suficiente para que um outro mundo se realize, mais justo e menos desigual, ou antes, estamos perante uma nova retórica burguesa sobre o capitalismo que mais não pretende, como aconteceu no passado, superar apenas a "crise de imagem" e esquecer todas as outras crises vividas em decorrência de sua próxima dinâmica de funcionamento?

O capitalismo consciente confronta-nos, mais uma vez, com a discussão em torno da grande questão que, sendo velha, permanece atual, confrontando liberais, 
sociais-democratas e marxistas: será o capitalismo reformável e capaz de proporcionar avanços sociais significativos ou, pelo contrário, as suas contradições e problemas sociais e ambientais decorrentes do seu funcionamento são insuperáveis, pelo que importa não perder de vista o horizonte da sua eliminação? Uma resposta crítica exige considerar o capitalismo como sistema histórico segundo o sentido dado, entre outros, por Wallerstein (1998), isto é, marcado pelas lutas entre classes sociais com interesses radicalmente distintos. Em contramão com os argumentos que o consideram como um sistema histórico irreversível e final - designado por Fukuyama (1992), no seu famoso livro, como o fim da história - , e sem negar a possibilidade de reformas e avanços relevantes para as classes trabalhadoras, como o Estado-Providência bem o exprime (cf., entre outros, Silva 2008 e Esping-Anderson com B. Palier, 2009), é nosso entendimento, subscrevendo as posições defendidas nomeadamente por Löwy (2013), Wallerstein (1999 e 2002) eSilva (2013), em linha com os argumentos de Marx e Engels (1968 [1848]), que as contradições sociais e ambientais produzidas pelo capitalismo fazem dele um sistema insustentável e, como tal, a superar no futuro.

O artigo comporta um ponto de vista teórico e político que recusa a neutralidade axiológica, tão inexequível como saltar sobre a própria sombra, segundo a imagem feliz proposta por Donham (1999), seguramente sugestionada pelas leituras de Lucky Luke, o cow-boy inventado por Morris (Maurice de Bévère) e René Goscinny (cf. Silva \& Ribeiro 2015). Em concreto, estamos perante um exercício de análise de alguns dos principais textos originais (ou das versões disponíveis em língua portuguesa) dos autores que são reconhecidos como os proponentes da versão consciente do capitalismo, ainda pouco discutido no campo da sociologia portuguesa. Neste exercício procura-se dialogar com os contributos de teóricos, alguns deles clássicos, que ora desenvolveram as ideias fundamentais do capitalismo, ora o criticaram de modo radical. Não nos cabendo apreciar a relevância nem a originalidade - ainda que se reconheça que, na esteira de Bourdieu, citando Montaigne, "nós só nos fazemos glosar uns aos outros" (Bourdieu, 2008 [1993], p. 693) - , foi nosso objetivo identificar se estamos perante uma nova configuração do capitalismo que pode contraditar as bases em que ele assenta ou, pelo contrário, se estamos face a mais uma reinvenção deste para combater a contestação e reforçar a sua legitimidade política e ideológica para continuar a existir, num momento em que a hegemonia, como diria Gramsci (1974), é confrontada com múltiplas contestações e críticas. 


\section{O capitalismo como sistema histórico}

Situar as origens do capitalismo continua a ser parte estimulante de um debate teórico e político que escrutina os seus elementos constitutivos, quando surgiram e o modo como se articulam para dar origem a um novo sistema político, a bem dizer, uma nova civilização, ora aniquilando, ora incorporando de forma subordinada outros modos de produção e de organização social. Para chegar a um sistema em que o lucro é o motor de toda a vida económica é preciso considerar também o papel desempenhado pelo Estado e por uma classe social, a burguesia, que acabaria por se transformar na classe social hegemónica, tomando o poder do Estado e fazendo com que este garantisse as condições políticas e jurídicas adequadas e necessárias aos seus interesses e aos vários processos de acumulação de capital e sua reprodução.

Como foi discutido por Ribeiro (2017), analisar as origens do capitalismo exige recuar aos séculos XV e XVI e à expansão marítima europeia. Esta vai conduzir à inserção de variados territórios, alguns de dimensão continental como a América, numa economia-mundo que, pouco mais de um século depois, teria por um tempo bem longo a Grã-Bretanha como seu centro político e económico. Esta economia-mundo capitalista foi alimentada pela acumulação de capital alicerçada na "expropriação violenta dos camponeses pelas enclosures, o tráfico de escravos e a pilhagem brutal das colónias" (Löwy, 2014, p. 1920). No entender de Marx e Engels

A descoberta de ouro e de prata na América, a extirpação, escravização e enterramento das populações autóctones nas minas, o começo da conquista e pilhagem nas Índias Orientais, a transformação da África numa espécie de coutada para a caçada comercial aos peles-negras assinalaram o despontar da era da produção capitalista. Estes processos idílicos são o ponto mais importante da acumulação primitiva. No seu seguimento vem a guerra comercial das nações europeias, com o globo como teatro. (Marx \& Engels, 1978, pp. 158-159)

Sem a subjugação de territórios e sua colonização brutal não se teria constituído a base que daria esteio às transformações tecnocientíficas que fizeram as revoluções industriais e consolidaram, doravante, o capitalismo e uma ordem social burguesa, na qual a propriedade, a utilização de trabalho assalariado e a obtenção de mais-valias passaram a ser garantidas pelo Estado. Estas transformações não se realizaram de modo instantâneo, com a rapidez decorrente de uma revolução, antes precisaram de vários séculos, conheceram avanços e recuos, articulando-se entre si e implicando lutas ferozes, vencedores e vencidos: 


\begin{abstract}
A grande indústria criou o mercado mundial preparado pela descoberta da América. $\mathrm{O}$ mercado mundial acelerou prodigiosamente o desenvolvimento do comércio, da navegação e dos meios de comunicação por terra. Este desenvolvimento reagiu por sua vez sobre a extensão da indústria; e, à medida que a indústria, o comércio, a navegação, as vias férreas se desenvolveram, crescia a burguesia, multiplicando seus capitais e relegando a segundo plano as classes legadas pela Idade Média. Vemos, pois, que a própria burguesia moderna é o produto de um longo processo de desenvolvimento, de uma série de revoluções no modo de produção e troca (Marx \& Engels, 1968 [1848], pp. 24-25).
\end{abstract}

Não cabendo aqui alimentar aprofundadamente esta discussão, procura-se sobretudo sublinhar o seu caráter histórico, logo produto das lutas sociais e da ação humana, e recusar a naturalização com que não raro se entende o capitalismo, em especial um dos seus principais elementos, o mercado (cf. Polanyi, 1983 [1944]). Em linha com os argumentos de Wood (2001), o capitalismo não tem data de nascimento precisa. ${ }^{2}$ Em sociedades e épocas históricas anteriores estavam já presentes muitos dos seus elementos fundamentais, com realce para a moeda e o mercado. Neste sentido, pode-se perceber que o capitalismo não é apenas a moeda, o mercado, mais o capital, o trabalho assalariado, a propriedade privada ou qualquer outro elemento que o constitui, mas sim

\begin{abstract}
um sistema em que os bens e serviços, inclusive as necessidades mais básicas da vida, são produzidos para fins de troca lucrativa; em que até a capacidade humana de trabalho é uma mercadoria à venda no mercado; e em que, como todos os agentes econômicos dependem do mercado, os requisitos da competição e da maximização do lucro são as regras fundamentais da vida. [...] Acima de tudo, é um sistema em que o grosso do trabalho da sociedade é feito por trabalhadores sem posses, obrigados a vender sua mão-de-obra por um salário, a fim de obter acesso aos meios de subsistência. No processo de atender às necessidades e desejos da sociedade, os trabalhadores também geram lucros para os que compram sua força de trabalho. Na verdade, a produção de bens e serviços está subordinada à produção do capital e do lucro capitalista. O objetivo básico do sistema capitalista, em outras palavras, é a produção e a autoexpansão do capital (Wood, 2001, p. 12).
\end{abstract}

Discutir teoricamente o capitalismo impõe convocar a Grã-Bretanha dos séculos XVIII e XIX e intelectuais como David Ricardo, John Stuart Mill, Thomas Malthus e, acima de qualquer outro, Adam Smith. Retomando o já enunciado em Ribeiro (2017), o filósofo e economista escocês procurou entender como a riqueza das nações se produzia. Como argumentam Louçã e Caldas (2009, p. 56), tal implica caraterizar a riqueza, analisar as diferenças existentes entre as nações e conhecer as formas que permitem o enriquecimento das nações. Friedman e Friedman anotam que, em A Riqueza das Nações, Smith 
analisa a maneira como um sistema de mercado pode combinar a liberdade dos indivíduos que têm determinados objectivos com a colaboração extensiva e cooperação necessária ao campo económico para produzir a nossa alimentação, vestuário e habitação. A opinião de Adam Smith é que, numa troca, ambas as partes podem beneficiar e que, desde que a cooperação seja estritamente voluntária, a troca só se verificará quando as duas partes beneficiarem. [...] É por isso que, tal como Adam Smith diz, um indivíduo que "só pretende o seu próprio lucro é levado por uma mão invisível a defender um fim que não fazia parte da sua intenção. Procurando defender o seu próprio interesse, ele promove, frequentemente com maior eficácia, os interesses da sociedade" (Friedman \& Friedman, 1980, pp. 29-30).

Defensor férreo da chamada "mão invisível" e da sua centralidade na organização da economia, Smith considerava que os indivíduos deveriam atuar com a mais completa liberdade, de forma a assegurar a máxima eficiência no funcionamento do mercado. O filósofo e economista escocês introduz um dos conceitos que permanece como um dos princípios basilares do liberalismo: a "mão invisível", acima referida por Friedman e Friedman (1980), por via da qual os interesses pessoais e egoístas dos indivíduos se comutam em vantagem para toda a sociedade:

Não é da bondade do homem do talho, do cervejeiro ou do padeiro que podemos esperar o nosso jantar, mas da consideração em que eles têm o seu próprio interesse. Apelamos, não para a sua humanidade, mas para o seu egoísmo, e nunca lhes falamos das nossas necessidades, mas das vantagens deles (Smith, 1999b [1776], p. 95).

Porém, é necessário contextualizar e discutir este egoísmo considerando os termos em que o próprio Smith o faz. Como justamente lembram Louçã e Caldas (2009, pp. 57-58), a liberdade de cada indivíduo na sua ação egoísta deve acatar as "leis da justiça", constituindo imperativo do Estado amparar as pessoas contra as injustiças, demoradamente analisadas na Teoria dos Sentimentos Morais, publicada originalmente em 1759. Por outras palavras, como foi também defendido por Ribeiro (2017), a adscrição da economia a princípios não económicos, logo morais e éticos, está inquestionavelmente presente no pensamento do filósofo e economista escocês, aliás em linha com a interpretação de Viveret (2006, p. 174). Não obstante defender que as pessoas têm uma tendência natural para procurarem os seus interesses, Smith (1999a [1759]) argumenta que a instituição de princípios morais se faz por via da simpatia, entendida como um sentimento instintivo, logo natural. Sublinhando que a sociedade é indispensável aos indivíduos, a simpatia assume-se como uma categoria fundamental para a produção do bem-comum através da imaginação da situação do outro, principalmente sempre que enfrenta dificuldades, proporcionando a constituição de uma ética na qual cada pessoa não almeja a 
desgraça e a infelicidade alheias. Não sendo um revolucionário, Smith coloca-se em contramão aos privilégios dos mais favorecidos, designadamente os logrados através de negócios monopolistas. Deste modo, é até admissível considerar que Smith não se opõe a reformas sociais, interpretação que colide com o entendimento de muitos, caso de Friedman e Friedman (1980). Estamos perante leituras truncadas de Smith, nas quais se celebram os comportamentos "egoístas" dos atores sociais - esteados no que se pode definir como um senso comum que entende o mercado como o modo natural e a-histórico de funcionamento da economia e o imaginado egoísmo dos indivíduos como elemento da natureza humana - , ignorando os valores morais e éticos que condicionam as ações humanas.

É precisamente na valorização destes princípios morais e éticos que parecem assentar alguns dos argumentos fundamentais dos teóricos do "capitalismo consciente". Não o questionando, antes procurando melhorá-lo, propõem uma agenda reformista para o capitalismo, apresentando um guia para ação dos capitalistas e suas empresas, para responder à instabilidade, estagnação e aos problemas agravados pela desigualdade crescente, tão intensa que se confunde mesmo com a que atingia as sociedades ocidentais na segunda metade do século XIX (Piketty, 2013).

\section{Reinventando o capitalismo?}

Sobre as origens e teses do capitalismo (dito) consciente e os argumentos dos seus críticos

O capitalismo consciente propõe um outro modo de funcionamento do capitalismo, no qual os benefícios decorrentes da atividade empresarial sejam partilhados de forma mais ampla por todos os chamados stakeholders, em contraposição ao modelo predominante ao longo da história do capitalismo, no qual predominou a maximização dos lucros em prol dos acionistas (Borrego, 2018; Chaves, 2014). Escrutinando-o em termos conceptual e teórico, esta nova versão do capitalismo é apresentada como um conceito definido a partir da publicação da obra Capitalismo Consciente: Como Libertar o Espírito Heróico dos Negócios. Escrita em 2013 pelo empresário norte-americano John Mackey e pelo professor indiano Raj Sisodia, foi sua ambição primeira facilitar a propagação pelo mundo do que no seu entender constituía uma proposta para um novo modelo de capitalismo. Como veremos, a crise é imprescindível para iluminar os argumentos mobilizados pelos autores nesta obra. No livro, Mackey e Sisodia procedem a uma discussão teórica onde pretendem estabelecer os fundamentos conceituais desta nova versão do capitalismo. No prefácio da obra argumenta-se que Mackey eSisodia "promovem o reencontro do capitalismo com suas raízes", sublinhado que este 
já foi melhor, tendo saído dos "trilhos" no último quarto de século, daí a contestação a que tem estado sujeito.

Sublinhe-se que o capitalismo consciente, apelando fundamentalmente à boa-vontade dos capitalistas e à construção de uma outra moral para a condução dos negócios, não se confunde com a agenda reformista de tipo keynesiano, institucional ou territorialista aplicada em numerosos países, em especial na Europa após a Segunda Guerra Mundial. Não só os teóricos do capitalismo consciente não valorizam estes contributos reformistas como parecem mesmo ignorá-los. Em momento algum é possível descortinar nos seus argumentos a defesa da intervenção do Estado na economia, regulando o laissez-faire e tolhendo as consequências dos diferentes ciclos económicos, em especial das crises de superprodução e decorrentes depressões que caracterizam o funcionamento do capitalismo, tal como foi discutido em A Teoria Geral do Emprego, do Juro e da Moeda, a obra seminal de Keynes (1996 [1936]). De igual modo, o capitalismo consciente não convoca o institucionalismo (cf. Myrdal, 1970 e 1974 [1957]; Schiavo-Campo \& Singer, 1970; Seers, 1969), em especial um dos seus argumentos fundamentais: as crises da economia capitalista são mais eficientemente sufocadas pela ação do Estado, pelo que se justifica que este implemente uma agenda política comprometida com a valorização dos interesses comuns, sendo a intervenção estatal crucial em áreas como a ciência, a tecnologia, as infraestruturas, a educação e a formação (cf. Aglietta, 2001; Silva \& Cardoso, 2005). O mesmo desinteresse dos teóricos do capitalismo consciente se aplica ao territorialismo (cf., entre outros, Long, 2001; Lopes 1980 e 1986; Reis 1998), ignorando as suas soluções fundadas no território e na valorização das capacidades dos atores a partir da exploração dos seus recursos e capacidades, tendo como objetivo a promoção do bem-estar humano.

Olhando para as raízes do capitalismo, e fazendo tábua-rasa das fraudes e colapsos, nomeadamente creditícios súbitos que fazem a sua história, obliterando também os processos brutais, incluindo o genocídio, que estão na origem da acumulação primitiva de capital, já acima discutida, Mackey \& Sisodia (2013, p. 29) afirmam que, "embora o mundo dos negócios e o capitalismo não fossem perfeitos, eram fundamentalmente bons e éticos". No prefácio da edição brasileira, Flávio Rocha, acionista do Grupo Guararapes que, em 2016 e 2017, foi denunciado pelo Ministério Público do Trabalho e condenado pela justiça brasileira por submeter pessoas a condições de trabalho análogas à escravidão, vai mais longe na defesa do capitalismo como um sistema bom, ético, nobre e heroico, afirmando que "não há, portanto, quem, em qualquer nível da cadeia produtiva capitalista, não se beneficie com um sistema como esse" (Rocha, 2013, p. 14). Apesar de uma certa retórica laudatária, alguns dos principais teóricos, difusores e aplicadores do capitalismo 
consciente reconhecem que o capitalismo passa por uma "crise de imagem" (Rocha, 2013, p. 12) e, por isso, não é reconhecido pelo que realmente é:

Em vez de serem vistos pelo que realmente são - os heróis da história - , com grande frequência o capitalismo e os negócios carregam a fama de vilões e levam a culpa por quase tudo o que os críticos pós-modernos desaprovam no mundo. O capitalismo é acusado de explorar trabalhadores, ludibriar consumidores, promover desigualdades ao beneficiar ricos em detrimento de pobres, homogeneizar a sociedade, fragmentar comunidades e destruir o meio ambiente (Mackey \& Sisodia, 2013, p. 43).

O entendimento de Mackey Sisodia é de que o capitalismo sofreu distorções ao longo de sua história, provocadas por quatro elementos: (i) pelos homens de negócios "que permitiram que a base ética do capitalismo de livre-iniciativa fosse intelectualmente sequestrada por economista e críticos que atribuíram ao sistema uma identidade estreita, egoísta e imprecisa, desprovida de embasamento ético e coerente"; (ii) pelas empresas que operam com baixo nível de consciência a respeito de sua razão de existência na sociedade; (iii) pelo "mito de que as empresas devem se concentrar na maximização dos lucros", enraizados nas academias e corporações; (iv) pela interferência do Estado através do favorecimento de empresas a partir de relações políticas estabelecidas (Mackey \& Sisodia, 2013, pp. 43-44).

Procurando defender o capitalismo, a versão consciente apresenta-se como uma "correção da narrativa" (Mackey \& Sisodia, 2013, p. 54), um resgate do que é entendido por esta corrente como "o mais poderoso e criativo sistema de cooperação social e progresso humano jamais concebido" (Mackey \& Sisodia, 2013, p. 55), capaz de gerar prosperidade, tirar os indivíduos da pobreza e estabelecer condições estáveis para que famílias possam ser formadas. A bem dizer, estes autores tentam fazer com que o capitalismo consciente elimine as deformações produzidas pelo capitalismo ao longo do seu trajeto histórico, propondo o seu ancoramento em princípios que o fazem ser melhor. Um caminho aparentemente reformador do capitalismo, guiado pelos seguintes princípios: (i) propósito maior, quer dizer, a razão de existência de uma organização, razão esta capaz de guiar suas ações, estimular quem nela trabalha e gerar o lucro necessário e desejado numa organização capitalista; (ii) integração das partes interessadas, quer dizer, o entendimento de que um negócio implica o envolvimento de diversos atores e elementos, como fornecedores, clientes, trabalhadores, meio ambiente, sendo necessário considerar a importância de todos eles, bem como criar uma relação onde todos ganhem; (iiii) cultura consciente, quer dizer, um ambiente propício para o desenvolvimento do propósito maior e das relações de ganho mútuo entre as partes interessadas; (iv) liderança consciente, quer dizer, líderes com múltiplas inteligências, como a emocional e a 
espiritual, capazes de propiciar a criação e manutenção de ambientes conscientes para que a organização possa atingir seu propósito maior (Brasil, 2017; Mackey, 2011; Mackey \& Sisodia, 2013; O’Toole \& Vogel, 2011; Sisodia, 2011; Wang, 2013). Estes princípios, segundo Mackey e Sisodia (2013, p. 73), conduzem empresas conscientes a fazerem o certo porque acreditam que é certo, que é a "coisa correta, humana e digna a fazer".

Segundo Brasil (2017, p. 30), as empresas capitalistas conscientes são aquelas que têm consciência do seu impacto na sociedade, sejam eles positivos ou negativos, e, com isso, podem tomar decisões em favor de "um mundo mais sustentável, social, ecológica e economicamente". Mackey (2011) traz-nos a ideia de que o nível de consciência de uma organização passa pelo autoquestionamento sobre a razão de sua existência, o que ela tenta realizar e quais os valores centrais que inspiram a empresa e criam maior confiança e comprometimento de todas as suas partes interessadas. Já Sisodia (2011, p. 100) vai além, ao afirmar que o capitalismo consciente não se trata de um modelo de negócios, mas de "uma compreensiva filosofia de fazer negócios". Sendo um negócio capitalista, as empresas capitalistas conscientes não negam o lucro. Ao contrário disto, entendem que ser consciente pode gerar ainda mais lucro e de modo mais sustentado, com manifesta vantagem para os acionistas:

As organizações conscientes também se empenham em obter desempenho financeiro excepcional no longo prazo. Uma amostra representativa delas, por exemplo, superou o mercado global de ações (em uma relação de 10,5:1) em um período de 15 anos, oferecendo mais de $1600 \%$ de retorno total, enquanto a média de mercado no mesmo período foi de pouco mais de 150\% (Mackey \& Sisodia, 2013, p. 72).

Os autores e executantes do capitalismo consciente afirmam que a sua diferença está em colocar o lucro como consequência da aplicação dos quatros princípios fundamentais acima referidos, e não como fim a ser perseguido (Brasil, 2017; Mackey \& Sisodia, 2013), criticando mesmo um dos argumentos fundamentais de Milton Friedman, a saber: "a única responsabilidade da empresa é para com seus acionistas, [pelo que] os executivos que levam a sério suas responsabilidades de gerar emprego, eliminar a discriminação e conter a poluição [...] estão defendendo o puro socialismo" (apud George, 2013, p. 16). Apesar de Mackey (2011) considerar não existir nada de errado na procura de lucro por parte das empresas, este não deve configurar como um propósito inspirador e, se não há inspiração, não pode haver sucesso. A inspiração que leva ao sucesso, e consequentemente ao lucro, deve estar antes na criação de valor que uma empresa gera para as partes interessadas, nomeadamente acionistas, trabalhadores e clientes. Gerar valor para a sociedade e para o meio ambiente, sempre dimensões a considerar 
na visão do capitalismo consciente, é algo que é "organicamente relacionado à filosofia e ao modelo de funcionamento de qualquer empresa consciente" (Mackey \& Sisodia, 2013, p. 75).

Em contraponto, críticos do capitalismo consciente, como O'Toole e Vogel (2011), argumentam que, apesar de louvável e inovadora em alguns aspetos, a proposta acaba por não ter aplicabilidade num universo largo de empresas e, assim sendo, acaba por "prometer mais do que pode entregar" (O'Toole \& Vogel, 2011, p. 73). De entre algumas destas promessas identificadas por estes autores ( $\mathrm{O}^{\prime}$ Toole \& Vogel, 2011), as quais entendem que não são aplicáveis às diversas empresas, sobretudo as de menor porte económico, estão o tratamento generoso dos trabalhadores, bem como entrega de produtos melhores a grande parte da população, uma vez que, segundo eles, produtos melhores são mais caros e, assim, só são acessíveis a uma camada afluente de consumidores. Mas não só, existem condições produtivas que geram problemas que ultrapassam em escala e competência aquilo que uma organização pode fazer por si só. Um bom exemplo desta difícil aplicabilidade de consciência em larga escala, está na "dificuldade de se pensar em como uma empresa de carvão poderia abraçar os princípios e práticas de sustentabilidade ambiental (O'Toole \& Vogel, 2011, p. 73).

Wang (2013), outro crítico da aplicabilidade do capitalismo consciente em larga escala, entende que os seus proponentes quase que exclusivamente atribuem à elevada consciência o caminho para que as empresas adiram ao movimento capitalista consciente, desprezando assim a dimensão estrutural, isto é, as condições materiais em que os empresários atuam. Para ele, isto não é suficiente, devendo ser levado em consideração outros fatores que fazem com que, ainda que defendido pelos seus proponentes como um modelo de negócio superior e mais lucrativo, o capitalismo consciente ainda seja uma prática rara no mundo real (Wang, 2013). Neste sentido, Wang (2013, p. 103) questiona: "por que apenas um pequeno punhado de companhias escolhem ser empresas capitalistas conscientes?" [...] "porque a vasta maioria de empresas não escolheu seguir este processo?".

As interpelações de Wang encontram pertinência na hipótese de que a defesa tão veemente do capitalismo por parte de Mackey e Sisodia se explica por estes aceitarem a acumulação capitalista, não tendo interesse em interrompê-la. Apesar de afirmarem diversas vezes que o lucro não é um objetivo a ser perseguido, mas somente um elemento importante na vida dos negócios e das pessoas, os teóricos do capitalismo consciente não colocam em causa os fundamentos e sobretudo as consequências do funcionamento do sistema capitalista, nomeadamente as relacionadas com as desigualdades e a concentração da riqueza, antes sugerindo que os problemas se resolvem através de uma fórmula idealista que tem como alavanca transformadora 
a procura do que chamam de "um mundo de compaixão, liberdade e prosperidade" (Mackey \& Sisodia, 2013, p. 34). Tal significa que este apelo idealista à boa vontade dos capitalistas descarta os seus interesses materiais que explicam largamente a voracidade do capitalismo decorrente das suas lógicas de acumulação, às quais não podem escapar nem a teoria do capitalismo consciente pode opor-se.

\section{Considerações finais}

Face a mais uma crise do capitalismo, sempre social e agora também ecologicamente devastadora, aos críticos que o censuram, procurando outros caminhos que exigem a sua superação, contrapõem-se os que, rejeitando esta, procuram melhores soluções dentro dele. É o caso do chamado capitalismo consciente. Amparados em alguns dos princípios morais expostos por Smith há dois séculos e meio, ainda que pareçam não lhes dar relevância, até mesmo bem conhecê-los, os defensores do capitalismo (dito) consciente propõem que o capitalismo seja o que, no seu entender, deveria ter sido ao longo da sua existência. Colocando-se em contramão dos críticos que questionam o capitalismo, entendem que os problemas que este tem criado, nomeadamente as desigualdades sociais, resultam da aplicação deformada dos princípios fundamentais do capitalismo. Embora se observe que o capitalismo consciente apresenta propostas que colidem com muitos argumentos liberais, sobretudo os elaborados por Friedman e Friedman (1980), as suas críticas ao lucro como o único objetivo da empresa não parecem suficientes para produzir uma distribuição equilibrada de riqueza e a universalização do bem-estar humano, ao evacuarem nomeadamente os interesses objetivos dos capitalistas e o ação do Estado. Daqui decorre que o capitalismo consciente se posiciona como um contributo para mais uma reinvenção do capitalismo, jogando um papel relevante para a superação do que designam simplesmente como "crise de imagem" que atualmente o atinge. E esta crise, que é muito mais do que de imagem, destapa as próprias contradições dos seus defensores, como é o caso de Flávio Rocha acima mencionado, afinal apenas mais um exemplo, a par de muitos outros, como revelam os casos da Volkswagen - responsável por uma fraude na emissão de gases dos seus motores - ou a Amazon - apontada por Mackey e Sisodia como uma empresa capitalista consciente - , justamente censurada por submeter os seus trabalhadores a condições laborais esgotantes e humilhantes nos seus armazéns de distribuição. Diante disto, pode-se concluir que as acusações ao capitalismo, entendidas por Mackey e Sisodia (2013) como injustas, estão devidamente amparadas por factos concretos.

Neste sentido, os argumentos de Mackey e Sisodia exprimem uma retórica sedutora, a bem dizer praticamente vazia de aplicação e consequências, que mais 
não faz do que procurar contribuir para manter o consentimento das classes trabalhadoras, sem o qual a sobrevivência dos capitalistas estaria em risco. Se olharmos para a história relativamente curta do neoliberalismo - que pode ser caracterizado como uma teoria de práticas de economia política que entende que o bem-estar será atingido de modo mais amplo por via da designada libertação da ação das forças empresariais e dos talentos individuais (Harvey, 2005, p. 2) - e a retórica em torno do "capitalismo popular e de proprietários", onde cada trabalhador passaria a ser também um acionista (Harvey, 2005, p. 219), constatamos que Mackey e Sisodia mais não fazem do que "baralhar e dar de novo" as cartas marcadas de sempre. Quer dizer, manter o fundamental, o necessário ao funcionamento do capitalismo e à subordinação da sociedade aos interesses burgueses, nomeadamente a propriedade das empresas por parte dos capitalistas e uma riqueza distribuída privilegiando os acionistas em detrimento dos trabalhadores.

Dotado de "sete vidas", permanentemente reinventado para continuar aquilo do qual não pode libertar-se - a obtenção, sob pena de morte, de mais-valias para os detentores do capital -, o capitalismo não desaparecerá por si próprio, nem a história, manifestamente, tem um sentido. Mesmo que a todo o tempo nos defrontemos com o insucesso da luta contra o capitalismo e sua incerta superação, aos teóricos e propostas de "humanização" do capitalismo, como é o caso da sua versão "consciente", é necessário, em contraponto, pensá-lo e agir fora do seu campo, como bem compreendeu Erich Unger há quase um século:

o ataque contra o "sistema capitalista" é fadado eternamente ao fracasso nos lugares de sua validade [...] para realizar alguma coisa contra o capitalismo é indispensável, antes de tudo, deixar [heraustreten] sua esfera de eficácia [Wirkungsbereich], porque, no interior dela, ele é capaz de absorver toda a ação contrária (apud Löwy, 2014, p. 106).

Foi, pois, guiados por este argumento luminoso do filósofo judeu alemão que fizemos a crítica da versão "consciente" do capitalismo, procurando não ser capturados pelas palavras encantatórias dos que propõem o "novo" para que o velho continue a prosperar.

\section{Agradecimentos}

Os autores agradecem aos revisores do artigo as apreciações e sugestões apresentadas que muito contribuíram para a elaboração de uma crítica aprofundada ao capitalismo, sem perder do horizonte a imaginação de alternativas que o possam superar. 


\section{Notas}

Por decisão pessoal, os autores escrevem segundo o novo acordo ortográfico.

1 Hay e Payne (2015) consideram que o capitalismo cívico implica a responsabilização do Estado na regulação do mercado, garantindo aos indivíduos o efetivo acesso aos serviços e bens públicos que, no seu entender, é elemento fundamental para a construção de uma sociedade mais justa. Daqui decorre colocar o capitalismo ao serviço das pessoas, em lugar de estas estarem coagidas pelas chamadas forças de mercado, especialmente constrangedoras nas versões mais liberais, como a que atualmente domina o sistema mundial capitalista.

2 Como foi já mencionado em Ribeiro (2010 e 2017), a naturalização do capitalismo, incluindo o mercado, tem na religião uma força enorme. Desde o teólogo inglês Richard Baxet no século XIX - Polanyi (1983 [1944], p. 186] refere que esse século ainda não tinha passado o seu equador e já o liberalismo económico se havia instituído em cruzada e o laisse-faire em fé militante - , muitos procuraram legitimar o capitalismo do ponto de vista religioso. Defendendo que o elemento fundador de um sistema é sempre religioso, alguns paladinos do capitalismo tentam sacralizá-lo. Michael Novak, por exemplo, considera o mercado como a materialização terrena do reino de Deus, na qual a empresa capitalista se assume como a "encarnação da presença de Deus [e a ação dos capitalistas numa] missão divina" (Sung, 1989, p. 121). Algo bem enunciado por Walter Benjamin, quando começa o seu famoso texto com a frase "devemos ver no capitalismo uma religião" (apud Löwy, 2014, p. 97). Antes de Benjamin, já Weber (1993 [1922]) tinha analisado o papel da religião, mais em concreto, da ética protestante no desenvolvimento do capitalismo, não como causa, mas como correlação entre esta e as lógicas e regras necessárias ao nascimento e expansão do capitalismo (Silva, 2009, p. 84).

\section{Referências}

Aglietta, M. (2001). El capitalismo en el cambio de siglo: La teoría de la regulación y el desafío del cambio social. New Left Review, 7, 16-70.

Arrighi, G. (1997). A ilusão do desenvolvimento. Petrópolis: Vozes.

Borrego, B. (2018). Purpose-driven profit: Evaluating the relationship between conscious capitalist efforts and financial performance in purpose-driven organizations. The University of Texas at Austin. Disponível em https://repositories.lib.utexas.edu/bitstream/handle/2152/65236/borregobentle y_Purpose-Driven Profit_2018.pdf?sequence=2

Bourdieu, P. (2008 [1993]). Compreender. Em P. Bourdieu (Dir.). La misère du monde (pp. 693-732). Petrópolis: Vozes.

Brasil, M. (2017). O discurso do réu: O que o capitalismo consciente tem a dizer em sua defesa?. Curitiba: Voo Pro. 
Chaves, V. F. (2014). A empresa do século XXI: Criando valor compartilhado em tempos de um capitalismo consciente. Interfaces Científicas, 2(3), 21-32.

Donham, D. L. (1999). History, power, ideology: Central issues in marxism and anthropology. Berkeley: University of California Press.

Esping-Anderson, G., \& Palier, B. (2009). Três lições sobre o Estado-providência. Porto: Campo da Comunicação.

Friedman, M., \& Friedman, R. (1980). Liberdade para escolher. Mem Martins: Europa-América.

Fukuyama, F. (1992). The end of history and the last man. Nova Iorque: The Free Press.

George, B. (2013). Prefácio: O capitalismo de volta aos trilhos. Em J. Mackey, \& R. Sisodia (Eds.), Capitalismo consciente: Como libertar o espírito heroico dos negócios. São Paulo: HSM Editora.

Gramsci, A. (1974). Obras escolhidas (Vol. I). Lisboa: Estampa.

Harvey, D. (2005). A brief history of neoliberalism. Oxford: Oxford University Press.

Hay, C., \& Payne, A. (2015). Civic capitalism. Cambridge: Cambridge Polity Press.

Keynes, J. M. (1996 [1936]). A teoria geral do emprego, do juro e da moeda. São Paulo: Nova Cultural.

Long, N. (2001). Development sociology: Actor perspectives. Londres: Routledge.

Lopes, A. S. (1980). Desenvolvimento regional: Problemática, teoria, modelos (Vol. I). Lisboa: Fundação Calouste Gulbenkian.

Lopes, A. S. (1986). Perspectivas de desenvolvimento (um ponto de vista). Em M. Silva (organização e prefácio), Portugal contemporâneo: Problemas e perspectivas (pp. 595-608). Lisboa: Instituto Nacional de Administração.

Louçã, F., \& Caldas, J. C. (2009). Economia(s). Porto: Afrontamento.

Löwy, M. (2013), Crise ecológica, crise capitalista, crise de civilização: A alternativa ecossocialista. Cadernos $\mathrm{CRH}, 26(67), 79-86$.

Löwy, M. (2014). A jaula de aço: Max Weber e o marxismo weberiano. São Paulo: Boitempo.

Mackey, J. (2011). What conscious capitalism really is. California Management Review, 53(3), 83-91.

Mackey, J., \& Sisodia, R. (2013). Capitalismo consciente: Como libertar o espírito heroico dos negócios. São Paulo: HSM Editora.

Marx, K., \& Engels, F. (1968 (1848]). Manifesto do Partido Comunista. São Paulo: Escriba.

Marx, K., \& Engels, F. (1978). Sobre o colonialismo (Vol. II). Lisboa: Estampa.

Myrdal, G. (1970). The challenge of world poverty. Londres: Allen Lane.

Myrdal, G. (1974 [1957]). Teoria económica e regiões subdesenvolvidas. Rio de Janeiro: Paz e Terra.

O'Toole, J., \& Vogel, D. (2011). Two and a half cheers for conscious capitalism. California Management Review, 53(3), 60-76.

Piketty, T. (2013). Le capital au XXIe siècle. Paris: Seuil.

Polanyi, K. (1983 [1944]). La grand transformation: Aux origines politiques et económiques de notre temps. Paris: Gallimard. 
Reis, J. (1998). O institucionalismo económico: Crónica sobre os saberes da economia. Notas Económicas, 11, 130-149.

Ribeiro, F. B. (2010). Entre martelos e lâminas: Dinâmicas globais, políticas de produção e fábricas de caju em Moçambique. Porto: Afrontamento.

Ribeiro, F. B. (2017). Uma sociologia do desenvolvimento. Vila Nova de Famalicão: Húmus.

Rocha, F. (2013). Prefácio da edição brasileira. Em J. Mackey, \& R. Sisodia (Eds.), Capitalismo consciente: Como libertar o espírito heroico dos negócios. São Paulo: HSM Editora.

Schiavo-Campo, S., \& Singer, H. W. (1970). Perspectives of economic development. Boston: Houghton Mifflin.

Seers, D. (1969). The meaning of development. IDS Communication, 44.

Silva, M. C. (2008). Prefácio à edição portuguesa. Em Gøsta Esping-Anderson, \& B. Palier (Eds.), Três lições sobre o Estado-providência (pp. 11-24). Porto: Campo da Comunicação.

Silva, M. C. (2009). Classes sociais: Condição objectiva, identidade e acção colectiva. Vila Nova de Famalicão: Húmus.

Silva, M. C. (2013). Crise, democracia e desenvolvimento: o lugar semiperiférico de Portugal. Revista Espanhola de Sociologia, (19), 153-168.

Silva, M. C., \& Cardoso, A. (2005). O local face ao global: Por uma revisitação crítica dos modelos de desenvolvimento. Em M. C. Silva, A. P. Marques, \& R. Cabecinhas (Orgs.), Desenvolvimento e assimetrias sócio-espaciais: Perspetivas teóricas e estudos de caso (pp. 23-79). Braga: Núcleo de estudos em Sociologia/Inovação à Leitura.

Silva, M. C., \& Ribeiro, F. B. (2015). Ciências sociais, ética e bioética: O caso do trabalho sexual. Revista Brasileira de Sociologia, 3(5), 178-202.

Sisodia, R. (2011). Conscious capitalism: A better way to win. California Management Review, 53(3), 98-109.

Smith, A. (1999a [1759]). A teoria dos sentimentos morais. São Paulo: Martins Fonte.

Smith, A. (1999b [1776]). Inquérito sobre a natureza e as causas da riqueza das nações (Vol. I). Lisboa: Fundação Calouste Gulbenkian.

Sung, J. M. (1989). A idolatria do capital e a morte dos pobres: Uma reflexão teológica a partir da dívida externa. São Paulo: Paulinas.

Viveret, P. (2006). Reconsiderar a riqueza. Brasília: Editora Universidade de Brasília.

Wallerstein, I. (1998). O capitalismo histórico (seguido de) A civilização capitalista. Vila Nova de Gaia: Estratégias Criativas.

Wallerstein, I. (entrevista com) (1999). Um sistema desmorona-se hoje sob os nossos olhos. Em Gérard Vindt (Ed.), 500 anos de capitalismo: A mundialização de Vasco da Gama a Bill Gates (pp. 148-153). Lisboa: Temas e Debates.

Wallerstein, I. (2002). A left politics for an age of transition. Monthly Review, (janeiro), 17-23.

Wang, C. (2013). Conscious capitalism firms: Do they behave as their proponents say?. California Management Review, 55(3), 60-87. 
Weber, M. (1993 [1922]). Economía y sociedad: Esbozo de sociología comprensiva. Cidade do México: Fondo de Cultura Económica.

Wood, E. M. (2001). A origem do capitalismo. Rio de Janeiro: Jorge Zahar Editor.

Data de submissão: 02/05/2019 | Data de aceitação: 20/02/2020 